\title{
O EXERCÍCIO DA LIBERDADE NA ÉTICA TRADICIONAL RIBEIRINHA PANTANEIRA AMPARADO NA DIALOGICIDADE E NA CRITICIDADE: REFLEXÕES TEÓRICAS ${ }^{1}$
}

\author{
Silvano Carmo de Souza ${ }^{2}$ \\ Amadeu José Montagnini Logarezzi ${ }^{3}$
}

\section{Resumo}

Originário do trabalho empírico para a elaboração de uma tese de doutorado desenvolvida com pescadoras e pescadores do Pantanal mato-grossense, este artigo reflete questões teóricas sobre alguns dos aspectos que demandaram maior aprofundamento durante a pesquisa. Inicia com uma discussão sobre a educação ambiental dialógico-crítica adotada, particularmente em relação aos adjetivos "dialógica" e "crítica", com destaque para a ênfase na dialogicidade como centralidade do processo. Sob a motivação da explicitação de uma ética tradicional ribeirinha pantaneira, passa a discutir o papel do trabalho na constituição dos sujeitos desse contexto e na emergência dessa ética, processos complexos que envolvem ainda outros conceitos importantes, como liberdade, necessidade, contingência, constrangimento e possibilidade. Tais conceitos também são abordados em seus aspectos mais fundamentais e no sentido adquirido no contexto da investigação empírica à qual referem-se estas reflexões.

Palavras-chave: Educação ambiental dialógico-crítica. Ética tradicional ribeirinha pantaneira. Educação ambiental com comunidades tradicionais no Pantanal.

\section{THE EXERCISE OF FREEDOM IN THE TRADITIONAL PANTANAL RIVERSIDE ETHICS SUPPORTED BY DIALOGUE AND CRITICALITY: THEORETICAL REFLECTIONS}

\begin{abstract}
This study, which refers to the empirical work of a doctoral thesis developed with fisherwomen and fishermen from the Pantanal of Mato Grosso, develops theoretical reflections on some aspects that demanded a greater depth during the research. It begins with a discussion about the dialogic aand critical environmental education adopted, particularly regarding the adjectives "dialogic" and "critical", emphasizing the dialogicality as the process centrality. Under the motivation to explain a traditional pantaneira riverside ethics, it begins to discuss the role of work in the constitution of the subjects of this context and in the emergence of this ethic. Complex processes involving other important concepts such as freedom, necessity, contingency, constraint and possibility, which are also addressed in their most fundamental aspects and in the sense they acquire in the context of the empirical research on these reflections.
\end{abstract}

Keywords: Dialogic and critical environmental education. Traditional riverside Pantanal ethics. Environmental education with traditional communities in the Pantanal.

\footnotetext{
${ }^{1}$ Este artigo foi elaborado no contexto de exigências do Programa de Pós-graduação em Ciências Ambientais da Universidade Federal de São Carlos. A tese de doutorado da qual ele faz parte é composta de cinco artigos, alinhavados entre si. Todos discorrem sobre os aspectos socioculturais do exercício da atividade pesqueira tradicional no Pantanal de Mato Grosso, da participação das pescadoras/es no âmbito da formulação de políticas públicas e da conservação da diversidade biológica de peixes.

${ }^{2}$ Doutor em Ciências Ambientais - Ambiente e Sociedade, Professor no Instituto Federal de Educação, Ciência e Tecnologia de Mato Grosso - Campus Cáceres Professor Olegário Baldo. E-mail: silvano.souza@cas.ifmt.edu.br

${ }^{3}$ Pós-doutor em sociologia, Professor titular aposentado da Ufscar e Professor no PPG em Ciências Ambientais da UfSCar. E-mail: amadeu@ufscar.br
} 


\title{
EL EJERCICIO DE LA LIBERTAD EN LA ÉTICA TRADICIONAL RIBEREÑA PANTANERA AMPARADO EN LA DIALOGICIDAD Y EN LA CRITICIDAD: UNAS REFLEXIONES TEÓRICAS
}

\begin{abstract}
Resumen
A partir del trabajo empírico de una tesis de doctorado sobre pescadoras y pescadores del Pantanal mato grosense, en este artículo se desarrolla reflexiones teóricas sobre algunos de los aspectos que demandaron una mayor profundización durante la investigación realizada. Se inicia con una discusión sobre la educación ambiental dialógico-crítica adoptada, más específicamente, con relación a los adjetivos "dialógico" y "crítico" poniendo énfasis en la dialogicidad como pieza central en el proceso. Bajo la motivación de una ética tradicional ribereña pantanera explícita, se pasa a discutir el papel del trabajo en la constitución de los sujetos de este contexto y la emergencia de esta ética, procesos complexos que todavía involucran otros conceptos importantes, como libertad, necesidad, contingencia, constreñimiento y posibilidad, los cuales también son abordados en sus aspectos más esenciales y en el significado que adquieren en el contexto de la investigación empírica con estas reflexiones.
\end{abstract}

Palabras clave: Educación ambiental dialógico-crítica. Ética tradicional ribereña pantanera. Educación ambiental en comunidades tradicionales en Pantanal.

\section{Introdução}

Neste artigo faremos inicialmente uma reflexão teórica sobre a educação ambiental dialógico-crítica, tratando de algumas características que consideramos elementares para sua consecução no campo da ação educativa popular transformadora, bem como sobre a escolha da adjetivação "dialógico-crítica". Também discorreremos sobre a ação dialógica freiriana como caminho de desvelamento e superação dos constrangimentos a que pescadoras e pescadores tradicionais ${ }^{4}$ são submetidas/os na região oeste do Pantanal de Mato Grosso. Nesse sentido - e tendo por base esse contexto - trataremos do papel do trabalho na constituição de sujeitos humanos às voltas com imposições restritivas ao exercício da busca por uma libertação que contemple suas possibilidades ontológicas no âmbito de uma ética tradicional ribeirinha pantaneira (SOUZA; LOGAREZZI, 2017, p. 122). Tal discussão nos levará ainda a discorrer sobre outros conceitos centrais, como liberdade, necessidade, contingência, constrangimento e possibilidade, na chave do compromisso ético que mobiliza as ações transformadoras de sujeitos que, cada vez mais conscientemente, vão fazendo história e nela se refazendo.

As reflexões teóricas que aqui apresentamos, de um lado, atenderam a demandas implicadas em investigação que envolveu longo processo de interação com as/os referidas/os pescadoras/es e, de outro, forneceu subsídios analíticos para o desenvolvimento daquele próprio trabalho, tendo em vista o exercício de uma práxis o mais dialógico-crítica possível. Tanto as reflexões teóricas, aqui recortadas e sintetizadas, como os aspectos empíricos, da metodologia à discussão dos resultados e do contexto aos sujeitos da pesquisa, estão descritos detalhadamente na referida tese.

\footnotetext{
${ }^{4}$ Pescadoras/es profissionais artesanais são aqui identificadas/os como pescadoras/es tradicionais, assim como na tese intitulada "Educação ambiental dialógico-crítica no Pantanal de Mato Grosso: a voz e o silêncio das pescadoras e dos pescadores tradicionais", como resultado de processo dialógico detalhado na referida tese (SOUZA, 2017, p. 19).
} 


\section{Dialogicidade e criticidade para uma educação ambiental transformadora}

No desenvolvimento de seu campo de atuação e, em particular, de sua área de produção de conhecimento, a educação ambiental incorporou historicamente uma expressividade polissêmica, refletida em uma série de termos a ela associados identitariamente, como criticidade, transformação, dialogicidade, ecopedagogia, emancipação, libertação, práxis, entre outros. Uma descrição sobre esta polissemia e a escolha aqui feita pelos adjetivos "dialógica" e "crítica" e, ainda, sobre as implicações na prática pedagógica pode ser encontrada em Souza (2017, p. 34-41).

Neste artigo teceremos algumas considerações a respeito da opção que fazemos quanto ao significado dos adjetivos escolhidos e quanto à ordem com que nominam o processo educativo ambiental: “dialógico-crítica". O primeiro destaque vai para o fato de que os adjetivos aparecem na expressão de forma coligada, o que implica constituírem assim um único adjetivo, que apresenta características tanto de dialogicidade como de criticidade e, no caso, de sua articulação. No entanto, ainda que haja tal fusão semântica em favor de um terceiro sentido maior, mais amplo, e que isso seja o que realmente mais importa em termos conceituais na nossa formulação do nome, apesar disso, há de se reconhecer também o valor implícito na ordem dos adjetivos componentes. Assim, discorremos a seguir sobre a antecedência no nome da dialogicidade ante a criticidade, tomando por base as elaborações de Logarezzi (2015) sobre fundamentos envolvidos no tema.

Devemos apontar, de saída, que ambas essas habilidades estão inscritas nas mais profundas e importantes essencialidades do ser humano. Tais elementos vêm se desenvolvendo desde os tempos da hominização, quando características especiais da nossa estrutura corporal (como o desenvolvimento do telencéfalo, do hipocampo e do polegar opositor em mãos liberadas pela postura ereta, entre outas) surgiram em meio aos desafios pela sobrevivência, pelo exercício da autoafirmação e da perseverança em sermos nós mesmos. Isso permitiu, então, o surgimento simultâneo da linguagem e da consciência, coincidentes com a criação de símbolos de sentido a tudo o que há, redundando, dessa forma, no mundo cultural, no trabalho humano, no gênero humano, enfim, em uma série de marcas próprias do ser social (FREIRE, 1987; FOLADORI, 2001).

Nesse construto histórico, evidencia-se um inacabamento persistente, num constante devenir (FREIRE, 1987) elaborado intersubjetivamente, constituinte, portanto, de nossa condição ontológica de seres sociais (inacabados e inacabáveis) que, através do trabalho, prosseguem em seu processo de humanização ao se transformarem em interações que transformam o mundo. Daí que somos seres livres capazes de nos aprimorarmos dinâmica e permanentemente, já que podemos conhecer, ainda que parcialmente, as relações causais necessárias da natureza como totalidade (aqui incluindo, portanto, tantos aspectos da relação metabólica com o ambiente como das relações sociais), além das contingências e dos constrangimentos que condicionam nosso campo de existência e ação nesse processo. Isso nos permite superar a condição adaptativa dos seres orgânicos, desenvolvendo uma transformação que nos implica dinamicamente no meio em que vivemos, permitindo nos reinventarmos no devir de nossa existência. A processualidade e o devir da nossa capacidade de inteligir o real nos potencializam para agirmos em conformidade com o gênero humano segundo nossa espontânea determinação, buscando enfrentar e superar as condições adversas sem que nenhum agente externo determine nosso agir no mundo, por mais que esses devam ser conhecidos e considerados (MARX, 2004; LUKÁCS, 2009; 2010; CHAUI, 2008; 2011).

Nesse contexto, vale destacar que, na perspectiva marxiana, o mundo, a realidade, é de natureza dialética. Por sua vez, uma representação da realidade que dê base a um pensamento crítico precisa ser necessariamente dialética. Mais: o próprio pensar deve ser dialético, não só porque ele está no mundo, mas porque ele constitui o mundo, e o faz também de forma dialética, 
na sua relação com a linguagem pela qual representa o mundo na consciência. Conforme destacou Freire (2005, p. 68), a partir desta base, há uma relação dialética fundamental entre pensamento, linguagem e mundo, de modo que cada um desses aspectos da nossa realidade surge e se desenvolve em estreita vinculação de mútua determinação com os demais em processo dinâmico e permanente. Não há como concebermos um sem os demais, consequência de estarmos no mundo, dele sermos conscientes, de representá-lo e de comunicá-lo.

Este "sermos conscientes" implica diretamente que pensamos o mundo, que o representamos mentalmente, que o elaboramos e reelaboramos, que o objetivamos em nossa subjetividade. E o "estarmos no mundo" significa, por sua vez, que convivemos socialmente, que estamos no mundo com as pessoas e com elas partilhamos nossas representações e elaborações do mundo, de modo que o processo deixa de ser solitário, puramente objetivo, passando a ser marcadamente intersubjetivo. Esta instância de elaboração do mundo por sua intersubjetivação coletiva, interativa, está diretamente associada à dialogicidade, enquanto, por outro lado, a instância de elaboração do mundo por sua objetivação individual, solipsista, está diretamente associada à criticidade. É importante notarmos que, em que pese essas associações mais diretas, tanto a criticidade comparece na intersubjetivação dialógica como a dialogicidade comparece na objetivação crítica. Daí tratarmos o "dialógico-crítico" como adjetivo único e de significado mais amplo, envolvendo o resultado desta fusão dialética de significados mais específicos.

A antecedência da dialogicidade explicita, por sua vez, uma escolha teórica que valoriza de modo especial as interações, as relações entre as pessoas de modo geral e, em particular, nos processos educativos. Também valorizamos as interações sujeito-objeto em que aparece eminentemente a criticidade e sua decorrente incorporação na subjetividade de quem pensa o mundo em sua interação com ele e pensa a si própria/o em interação consigo mesma/o. Mas entendemos que estes movimentos fundamentais de objetivação do mundo (e do eu que está no mundo, pensando) e sua elaboração subjetiva ganham especial potência quando se exercita sua comunicação em diálogo com elaborações de outras pessoas, não somente da perspectiva cognitiva, pela qual conhecemos o mundo, mas também da perspectiva axiológica, pela qual damos sentido ao mundo como um produto nosso e assim avaliamos nossas ações nele. A relação ainda assume a perspectiva política, pela qual conduzimos nossa participação no mundo - nos movimentos sociais e nos processos de decisão que marcam os rumos das sociedades em que vivemos.

Assim, principalmente com respeito ao contexto educativo, nos parece nítido que optar pelo acento da abordagem na relação sujeito-sujeito - tendo esta como catalisadora da relação sujeito-objeto - potencializa o processo como práxis comprometida com a transformação social. Uma educação ambiental dialógico-crítica, nesses termos, é uma educação que busca incorporar a dimensão ambiental de modo que as relações entre as pessoas e o diálogo aí presente ocupem um lugar central. Com isso, torna-se altamente relevante a intersubjetividade que marca o grupo e o seu desenvolvimento, já que esta característica coletiva condiciona as subjetividades tanto em interação individual com o mundo quanto em interação com as pessoas junto das quais se está no mundo. É a esse condicionamento que se refere Freire (1977, p. 66), quando diz que "é o 'pensamos' que estabelece o 'penso' e não o contrário". Ou seja, não podemos pensar sozinhos, pois não podemos ser sozinhos, já que só podemos nos constituir como humanos/sociais em interação dialógica com outras pessoas, mediada pelo mundo.

Além disso, faz parte da criticidade não somente objetivar o mundo que está fora da consciência, mas também objetivar esta parte especial do mundo que é a própria consciência enquanto o "que" pensa o mundo e o "como" o pensa, trazendo às elaborações objetivas da realidade o reconhecimento da limitação desta objetivação, considerando, por exemplo, os condicionantes históricos em que este "algo que pensa" e este "modo de pensar" vieram a se 
constituir como marca de uma subjetividade específica, redundando na diversidade de compreensões existente em um grupo de diferentes pessoas sobre um mesmo recorte da realidade, objetivamente único. Nesse sentido, essa complexidade que a criticidade apresenta torna-se, ela própria, mais um motivo para a valorização do diálogo como meio favorecedor do próprio desenvolvimento da criticidade, já que a diversidade de subjetividades enriquece a abordagem do processo educativo em suas potencialidades de conhecer e de se conhecer, de transformar e de se transformar, tudo isso historicamente, no mundo e com as pessoas no mundo, criticamente e dialogicamente, dialeticamente.

Foi no bojo do exercício de uma práxis impregnada dessas complexas conexões (no contexto pantaneiro já referido) que surgiu, ainda, a demanda por uma melhor compreensão de alguns conceitos-chave que passamos a abordar a seguir.

\section{O trabalho e a libertação no contexto da ética tradicional ribeirinha pantaneira}

Como discorremos em Souza e Logarezzi (2017, p. 112; 2018, p. 334), a atividade pesqueira tradicional ribeirinha desenvolvida no Pantanal de Mato Grosso é contrahegemônica5. A despeito de todas as históricas contribuições que estas comunidades tradicionais têm dado a esta região do país (MEDEIROS, 1999; PINHO et al., 2012), o Estado brasileiro, em consonância com os interesses do capital fundamentalmente alicerçado no agronegócio, insiste em negar-lhes direitos humanos fundamentais. Para essas mulheres e para esses homens, ser pescadoras/es pantaneiras/os lhes é condição ontológica. Assim, negar-lhes essa condição é uma forma de colonização de seu mundo da vida, no sentido de Habermas (2012). Com vistas à superação dos processos de desumanização, implicados nas ações de colonização, e consequente manutenção de sua cultura tradicional ${ }^{6}$, elas/es têm desenvolvido práticas sociais características de sua ética tradicional ribeirinha pantaneira (SOUZA; LOGAREZZI, 2017. p. 122), uma ética do bem viver pantaneiro. Em grande medida, decorrem dessas práticas sociais processos educativos dialógicos e críticos que dão sustentação à solidariedade e à generosidade com que (entre)tecem seu dia a dia. Também (em face da geopolítica regional) são desenvolvidos processos educativos substantivamente marcados pela resistência e pelo enfrentamento aos constrangimentos empreendidos pelo capital.

De acordo com esse sentido - da repercussão do anúncio das possibilidades de encontro dialógico que viabilize a busca por uma ética comprometida com a vida e com o respeito aos saberes tradicionais e da denúncia dos processos de desumanização que intentem colonizar o mundo da vida das pescadoras e dos pescadores tradicionais pantaneiras/os - é importante lançarmos aqui um olhar mais amplo e de fundo sobre esse recorte da realidade vivenciado por essas pessoas. $\mathrm{O}$ destaque deve recair sobre a atividade econômica em que se envolvem como seres humanos e sociais na particularidade de seu contexto espacial e temporal. Consequentemente, também destacamos a questão filosófica que nessa existência se instaura, em relação às noções de liberdade e de necessidade que marcam as escolhas e as ações dessas mulheres e homens em sua luta diária. Para tanto, tomamos por base a perspectiva marxiana na focalização do trabalho e a espinosana no tratamento mais direto das questões filosóficas,

\footnotetext{
${ }^{5}$ Nos termos gramscianos (GRUPPI, 1978), há um movimento contra-hegemônico nos enfrentamentos cotidianos empreendidos pelas/os pescadoras/es tradicionais no Pantanal de Mato Grosso, especialmente no que trata da defesa de seus territórios de pesca e de sua cultura.

${ }^{6}$ Diegues (2001, p. 82) considera que, a partir de uma perspectiva marxista, as culturas tradicionais, como a cultura tradicional ribeirinha das/os pescadoras/es pantaneiras/os, "estão associadas a modos de produção pré-capitalistas, próprios de sociedades em que o trabalho ainda não se tornou mercadoria, onde há grande dependência dos recursos naturais e dos ciclos da natureza, em que a dependência do mercado já existe, mas não é total. Essas sociedades desenvolveram formas particulares de manejo dos recursos naturais que não visam diretamente o lucro, mas a reprodução social e cultural; como também percepções e representações em relação ao mundo natural marcadas pela ideia de associação com a natureza e dependência de seus ciclos".
} 
embora, como veremos, os temas se impliquem mutuamente e, assim, suas abordagens aparecem imbricadas a seguir. Essas escolhas teóricas são compatíveis entre si, como se evidencia nos Manuscritos econômico-filosóficos, de Marx (2004), e na Ética, de Espinosa (2008), sobretudo por partirem da noção de uma totalidade a qual pertencemos e constituímos, sendo por ela constituídas/os, conforme veremos. Sobre essa discussão, que remete às condições e aos sentidos de nossas ações e de nossa existência, há ainda uma profusão de concepções distintas, de Aristóteles aos dias de hoje, como resume Chaui (2008, p. 331-340).

Começando pela atividade econômica, que se faz presente com grande autenticidade em seu mundo da vida, a pesca artesanal é experienciada por essas pescadoras e por esses pescadores como um precioso campo de identificação. Neste campo aparecem duas relações que caracterizam a maneira particular segundo a qual essas pessoas vivenciam sua ontologia: uma, de fundo, diz respeito à relação com o gênero e outra, mais imediata, diz respeito à relação com o trabalho - tomando-se esses conceitos na perspectiva ontológica marxiana do ser social, reelaborada por Lukács $(2009 ; 2010)$. Dizendo de outro modo: uma relativa ao ser que são e outra ao ser que estão vindo a ser, que estão permanentemente se fazendo ser, num complexo que inclui a relação dialética entre este e aquele, que, na verdade, são um só em seu inacabamento ontológico, marcado pela própria natureza do trabalho humano em sua relação de recíproca e dinâmica vinculação à generidade do humano.

Ainda nesse complexo de mutualidade de determinações, assim como esses seres são (e estão sendo em) um só, também as relações desses com o gênero a que pertencem e com o trabalho que exercem podem ser vistas como entrelaçadas em uma relação dialética mais ampla que marca ontologicamente o ser social que são e que, ao mesmo tempo, estão vindo a ser. Isso tudo sempre como resultado de um processo histórico em que, ao aprimorar o suporte ambiental da vida, esses seres criam e desenvolvem também o mundo simbólico da existência, da cultura e da sociabilidade, nos termos de Marx (2004) e de Freire (1987). De modo geral, o estágio histórico em que nos encontramos como humanidade (na plenitude do capitalismo - transição do século XX para o XXI) é visto, da perspectiva marxiana, como um limiar da pré-história do nosso desenvolvimento ontológico e, nesse sentido, conforme aponta Lukács (2010, p. 75-76). Marx nunca cessou de avistar no desenvolvimento da generidade o critério ontológico decisivo para o processo de desenvolvimento humano. O contínuo destaque dado ao recuo das barreiras naturais, como característica da realização da sociabilidade, já aponta para essa concepção.

O pertencimento ao gênero (humano) e o exercício do trabalho (humano) se implicam mutuamente na constituição do ser humano, mas de um modo radicalmente distinto, superando a mudez da relação dos seres (puramente) orgânicos com seus respectivos gêneros.

$\mathrm{Na}$ natureza orgânica, onde o processo de reprodução significa ontologicamente adaptação ao ambiente, pode-se já falar de êxito ou de fracasso; mas também essa oposição não ultrapassa - precisamente do ponto de vista ontológico - os limites de um mero ser-de-outro-modo (LUKÁCS, 2009, p. 231).

Por sermos seres sociais, dotados de consciência, participamos cotidianamente da construção da generidade e somos simultaneamente condicionados por ela em nossa própria essencialidade, embora, em muitos casos, possamos não ter consciência plena desse papel e dessa influência. Em todo caso, como apresentado em Souza (2017), nossa relação com o ambiente vai muito além da pura adaptação dos seres orgânicos (ser-de-outro-modo), envolvendo a escolha consciente de meios e fins nos processos de transformação presentes em nosso dia a dia, com destaque para o exercício do trabalho como atividade econômica de produção e reprodução da vida. Mas, além disso, a relação envolve ainda significação e simbolização, implicando valor e dever-ser, levando a comportamentos cada vez mais espiritualizados e a uma teia cada vez mais complexa de conhecimentos e de condições que 
devem ser consideradas nas decisões teleologicamente tomadas. Ou seja, diferentemente dos demais seres, nós enfrentamos as barreiras interpostas em nosso existenciar e, com isso, nos refazemos como seres, nos transformamos nesse processo de enfrentamento (ser-outro-ser). Podemos aqui acrescentar a perspectiva freiriana que destaca ser dialógico este processo de enfrentamento e transformação da realidade, numa dialogicidade que se alia à dialeticidade/criticidade, como descrevemos acima.

Esse processo é caracterizado tanto pela possibilidade de escolhas livres a respeito de nosso agir como pelas restrições decorrentes de que esse agir se dá, sempre, em um ambiente material e em um contexto cultural que possuem leis, regras e normas próprias. $\mathrm{O}$ condicionamento implicado nessas restrições marca assim a essência de nossa natureza humana e social e é, em geral, referido teoricamente por meio do par necessidade e liberdade, que, nas concepções mais tradicionais, é tratado como uma oposição. Por isso, antes de continuarmos com a explanação em curso, focalizaremos brevemente nossa escolha conceitual a respeito dessas noções fundamentais às elaborações desta tese.

Vale ressaltar, inicialmente, que as elaborações sobre liberdade e necessidade têm uma importante referência na ética, cujas concepções teóricas "procuram sempre enfrentar o duplo problema da necessidade e da contingência, definindo o campo da liberdade possível", como comenta Chaui (2008, p. 334). Em meio a várias concepções sobre esse instigante tema, discorreremos a seguir sobre a de Espinosa, que guarda compatibilidade com a de Marx e Lukács, como dissemos, e aqui nos interessa.

Nesse sentido, vale conceituarmos previamente alguns termos centrais ao tema, tomando por base elaborações consolidadas desde Aristóteles, indicadas por Chaui (2008, p. 334). A expressão necessidade refere-se a algo condicionado externamente e, portanto, deve ser necessariamente atendido nas escolhas que fazemos, como, por exemplo, a lei da gravidade ou uma lei anti-imigração (importante observar as marcas objetiva de uma e subjetiva de outra). Já a contingência é algo que acontece ao acaso, sem escolha deliberada, e que não temos como evitar, como, por exemplo, a queda de um meteorito ou nossa maternidade, paternidade, nacionalidade etc. Enquanto a contingência é o puro acaso, por sua vez, o possível é algo que pode acontecer desde que alguém delibere e decida realizar uma ação, como, por exemplo, preparar uma mojica de pintado acompanhada de salada tropical ou entrar em um curso universitário. Obviamente, este algo só poderá ser realmente possível nos casos em que se tem acesso ao peixe e aos demais ingredientes demandados, bem como aos utensílios etc., ou em que se possa ter uma formação adequada e acesso ao respectivo vestibular, aos documentos, aos recursos e outros. Caso contrário, a decisão, tomada voluntariamente, acabará sendo restringida (por agentes externos) apenas à vontade, que, esta sim, em princípio não é causada nem limitada por nenhum agente externo.

Nesses termos, Aristóteles já elaborava sua noção de liberdade, como o princípio da escolha entre alternativas possíveis, realizado como decisão e ato voluntário, sem constrangimentos externos ou internos, sem nada que a impele e nada que a impede. Esta perspectiva opõe a liberdade à necessidade e à contingência, sob as quais o agente sofre a ação de uma causa externa que o obriga a agir de uma determinada maneira, enquanto, por sua vez, no ato voluntário livre, o agente é ele próprio causa de si e de sua ação. Devemos admitir que a vontade, embora não seja determinada ou causada pela razão, é por esta condicionada, na medida em que a direciona, mas não a obriga ou a constrange, de modo que podemos, inclusive, decidir e agir contrariamente à razão. "É por ser livre e incondicionada que a vontade pode seguir ou não os conselhos da consciência. A liberdade será ética quando o exercício da vontade estiver em harmonia com a direção apontada pela razão" (CHAUI, 2008, p. 334). Ainda nesta chave da referida oposição conceitual, Sartre observa que, mesmo ao nos considerarmos resignados, cansados ou fracos diante de um desafio, a decisão sempre vai depender fundamentalmente de nós mesmos, de um autojulgamento de nossa atitude, de nossa disposição 
ou de nossa força. Afirmando que, nesse sentido, é a liberdade que define a nossa humanidade, ele postula o paradoxo de que nós estamos condenados à liberdade, no sentido de que ela seja parte inescapável de nós mesmos.

Como se sabe, no século XVII, Espinosa desenvolve um pensamento que rompe profundamente com importantes concepções anteriores e em voga, incluindo as recémelaboradas ideias de Descartes. Assim como já se pensara no estoicismo e como se viria a pensar no hegelianismo, desvia-se da chave da oposição entre liberdade, de um lado, e necessidade e contingência, de outro. Espinosa, bem como essas duas outras correntes, não situa a liberdade no ato de escolha realizado pela vontade individual separada da necessidade e oposta a ela, mas a coloca na atividade de cada uma e cada um enquanto parte de um todo necessário - isto é, um continente a que necessariamente pertencem todos os seres que nele existem ${ }^{7}-$, o qual age livremente porque age necessariamente (CHAUI, 2008, p. 335). Este todo pode ser entendido como a natureza ou a substância infinita, em Espinosa (2008, p. 13), uma totalidade como poder absoluto de ação, agindo segundo seus próprios princípios, dando a si mesma suas leis, regras e normas. Por agir apenas por seu poder interno - pois nada lhe é nem pode ser externo -, tais ações ou determinações são livres. E, visto que essa ação provém da essência ou do próprio ser do todo, sua ação não é contingente nem meramente possível, mas é necessária, decorre necessariamente da simples existência e essência da natureza ou da substância infinita. "É porque o todo é o que é ou possui o ser que possui que ele age da maneira como age" (CHAUI, 2008, p. 335). É pela necessidade da essência ou do ser da substância infinita (ou da natureza) que esta age e por isso sua ação flui espontânea e necessariamente dela mesma. "Seu agir é uma necessidade livre ou uma liberdade necessária porque a necessidade não é um poder externo que a força a agir, mas é apenas a lei interna de sua própria ação, lei que ela dá a si mesma" (CHAUI, 2008, p. 335), sendo esta totalidade o "Deus imanente" descrito na primeira parte da Ética de Espinosa (2008, p. 10-75), em que se afirma ainda que "o intelecto de Deus é causa, tanto da essência, quanto da existência de nosso intelecto" (ESPINOSA, 2008, p. 43).

Como argumenta Chaui (2008, p. 335),

esta totalidade, necessária e livre em si mesma porque nada a força ou a obriga do exterior, instaura, pela ação de sua liberdade, leis e normas necessárias para toda a realidade ou para todas as suas partes (os indivíduos constituídos por ela).

Assim, diferentemente das concepções anteriores, liberdade, aqui, não é um poder incondicionado para escolher (a natureza ou a substância infinita não escolhem), mas é o poder do todo para agir em conformidade consigo mesmo, sendo necessariamente o que é e fazendo necessariamente o que faz. Com isso, ter liberdade não é escolher ou deliberar, mas agir ou fazer alguma coisa em conformidade com a natureza do agente.

Considerando agora que o agente não seja esse todo (livre, necessário etc.), mas uma pessoa - que é parte integrante desse todo -, o que seria então a liberdade humana? Nesse caso,

Espinosa afirma que as partes são de mesma essência que o todo e, portanto, são racionais e livres como ele, dotadas de força interior para agir por si mesmas, de sorte que a liberdade é tomar parte ativa na atividade do todo. Tomar parte ativa significa, por um lado, conhecer as condições estabelecidas pelo todo, conhecer suas causas e o modo como determinam nossas ações, e, por outro, graças a tal conhecimento, não ser um joguete das condições e causas que atuam sobre nós, mas agir sobre elas também. Não somos livres para escolher tudo, mas o somos para fazer tudo quanto esteja de

\footnotetext{
${ }^{7}$ Vale destacarmos aqui a distinção entre o que expressamos como continente e o que se costuma entender por universo. Tal continente, ao conter tudo o que há na natureza, na concepção espinosana, abarca, para além do universo das coisas extensas com suas dimensões físicas que se mobilizam pelo espaço há cerca de 13 bilhões de anos, ainda o mundo das ideias (das coisas pensantes), das significações das coisas e dos sentidos do existir (da criação do mundo pela intelecção das coisas, subjetiva e intersubjetivamente), também esta uma componente da natureza como totalidade, uma outra forma de manifestação da mesma substância infinita da qual tudo deriva ou, ainda, um outro modo de atributo de Deus.
} 
acordo com nosso ser e com nossa capacidade de agir, graças ao conhecimento que possuímos de nós mesmos e das circunstâncias em que vamos agir (CHAUI, 2008, p. 335 , grifos da autora).

Assim, para Espinosa, o ser humano livre é aquele que age como causa interna, completa e total de sua ação. E não é por uma escolha voluntária que se decide e se realiza uma ação, mas a decisão e a realização da ação provêm do desenvolvimento espontâneo da essência ou natureza racional do agente. Assim, o indivíduo livre age por necessidade de sua própria essência, tal qual acontece com o todo, como vimos.

Para o filósofo,

somos livres quando somos uma potência interna para a pluralidade simultânea de afetos, ideias e ações que decorrem de nosso próprio ser e dos quais somos a única causa. Em outras palavras, somos livres quando o que somos, o que sentimos, o que fazemos e o que pensamos exprime nossa força interna para existir e agir (CHAUI, 2008, p. 335).

Com isso, Espinosa nega a ideia dos estoicos de um poder imperial da vontade sobre as paixões: "não somos livres porque nossa vontade domina nossas paixões, mas é porque somos livres que nossa razão é um afeto alegre mais forte do que os afetos nascidos das paixões" (CHAUI, 2008, p. 335).

Há ainda outro aspecto na concepção espinosana que é de grande interesse para esta pesquisa, apontado por Chaui (2011) com base em cartas trocadas entre Espinosa e seus interlocutores no século XVII, descobertas no século XX. Nesses documentos, segundo a autora, Espinosa desloca a clássica oposição entre liberdade e necessidade para a oposição entre liberdade e constrangimento, sendo que "o que diferencia o constrangimento da liberdade não é a ausência (nela) ou a presença (nele) da necessidade, mas a interioridade ou exterioridade da causa que incita a existir e agir" (CHAUI, 2011, p. 273-274). Ou seja, o necessário não é o constrangido, como se supusera desde Aristóteles. Naquela tradição, tínhamos que admitir que o livre não pode ser necessário. Espinosa faz ainda outra correção nos termos daquela concepção, excluindo 'a diferença entre 'por natureza' e 'por vontade', a primeira expressão significando 'por necessidade', e a segunda, 'por liberdade'” (CHAUI, 2011, p. 274). É por isso que, para Espinosa,

a diferença entre Deus e a pedra não consiste na presença de uma vontade no primeiro e na ausência dela na segunda: liberdade não é livre decisão de uma vontade, mas a necessidade interna de uma essência de existir e agir segundo a necessidade das determinações que lhe são próprias. Sendo causa de si, Deus age pela livre necessidade de sua essência, enquanto a pedra, em decorrência de sua finitude, de sua natureza extensa e do princípio de inércia que rege todos os corpos, entra em movimento ${ }^{8}$ [acelerado] e nele permanece apenas se houver uma causa exterior [uma força] que a constranja a mover-se [em aceleração] (CHAUI, 2011, p. 274).

Isto é, a pedra, diferentemente dos seres sociais, toma parte passiva na atividade do todo porque, não sendo racional, não pode conhecer as causas e os modos de determinação da sua ação e, assim, não podendo agir sobre tais causas e modos, tem suas ações causadas e determinadas por outros agentes, como um joguete em poder destes. Daí que nossa liberdade esteja intrinsecamente associada à nossa consciência.

Nesse momento, importa retomarmos e ampliarmos a descrição do problema a ser enfrentado por nós no campo da ética envolvendo o complexo da liberdade. Podemos delimitá-

\footnotetext{
${ }^{8}$ Consideramos aqui o conceito de inércia newtoniano, segundo o qual os corpos que não são "constrangidos" por nenhuma força (resultante) tendem a permanecer em movimento retilíneo uniforme, sendo o estado de repouso apenas uma particularidade deste. Os complementos entre colchetes procuram então atualizar o texto, elaborado com base na mecânica pré-newtoniana, sem nenhum prejuízo da exemplaridade conceitual pretendida por Espinosa.
} 
lo a partir de determinações internas (causa interior - necessidade interna de uma essência de existir e agir segundo a necessidade das determinações que lhe são próprias) e externas (causa exterior - necessidade externa a uma essência de existir e agir segundo a necessidade de determinações que não lhe são próprias) que condicionam nossas possibilidades de existir e agir.

Implicam determinações externas, como vimos, a necessidade e a contingência, sendo a primeira decorrente de relações causais por nós conhecíveis e ponderáveis e a segunda decorrente de relações causais conhecíveis, mas imponderáveis por serem também casuais, quando muito, podendo, no primeiro caso, serem contornadas/atendidas/controladas e, no segundo, serem aceitas e eventualmente prevenidas/direcionadas. Ambas, necessidade e contingência, são inevitáveis, uma vez que suas determinações não partem de nós, embora as possamos conhecer, ainda que limitadamente. Por sua vez, como vimos em Espinosa, a liberdade implica determinações internas, atinentes a relações que nós mesmos determinamos em nosso existir e agir no mundo, sendo que, obviamente, essas determinações (internas) devem considerar as determinações (externas) da necessidade e da contingência que também fazem parte do todo em que criamos nosso mundo sociocultural, no qual exercemos nossa liberdade.

Essa distinção conceitual que põe liberdade, de um lado, e necessidade e contingência, de outro, torna-se mais complexa e menos nítida quando consideramos a presença dos constrangimentos, uma vez que não é simples definir sobre sua interioridade ou exterioridade a nossa essência de existir e agir. Tal dificuldade decorre de nossa ontologia de ser inacabado, o que põe uma margem de nossa essência em constante (re)(co)elaboração cultural. Nesse sentido, se pensamos ser seres sociais, tal essencialidade implica restrições intrínsecas para existir e para agir, uma vez que nosso estar no mundo deve se dar em convivência social, pois não podemos nos constituir como o ser que somos, ontologicamente, a não ser em meio a relações sociais. Por isso, limitações ou constrangimentos relacionados às regras sociais e às normas morais, tácitas ou explícitas, em princípio, devem ser considerados decorrentes de relações causais provenientes de nossas próprias determinações - portanto internas a nossa essência de existir e agir (como ser social que somos).

A nuance surge na definição de quais limitações desse tipo podem ser identificadas com nossa essência de existir e agir e, assim, ser consideradas como advindas de determinações internas a nós, não caindo na chave do constrangimento - dito no sentido indicado por Espinosa? E, por outro lado, quais limitações que, embora também sejam atinentes a nossas próprias determinações, não podem ser identificadas com nossa essência de existir e agir? Em outros termos: quais limitações atenderiam a necessidades de determinações que são próprias da nossa essência de existir e agir e quais atenderiam a necessidade de determinações que não são próprias de tal essência? Tais questões esbarram na discussão de fundo a respeito da concepção de ser e de sociedade/mundo que somos e constituímos, refletindo a essência implicada nos questionamentos. E, como os fazemos com base em nossas eticidade e politicidade, vivemos uma discussão permanentemente aberta a esse respeito, relacionada com as direções da trajetória histórica de desenvolvimento das sociedades. Portanto, as respostas profundas a essas questões exigem irmos muito além da discussão sobre legalidade e legitimidade, envolvendo aspectos mais complexos da democracia, da cultura, da ideologia, da ontologia.

Nesse contexto, uma mesma determinação pode ser postulada como consistente ou inconsistente a nossa essência de existir e agir, em casos em que a concepção de ser e de sociedade varie substancialmente. Por exemplo, uma concepção pode admitir que a desigualdade social seja uma essencialidade nossa, algo inerente a nosso modo se ser, de existir e de agir, enquanto outra pode conceber a mesma desigualdade social como um desvio de nossa essência historicamente construído em desconformidade com o gênero humano e, portanto, que demanda superação. Para a primeira concepção, regras que apontam para a conservação de um 
mundo socialmente desigual, como acontece no âmbito dos conflitos socioambientais em que as pescadoras e os pescadores tradicionais estão inseridas/os, podem ser consideradas como uma determinação interna, uma determinação ontológica, e serem associadas ao exercício da liberdade. Na segunda concepção, por sua vez, essas mesmas regras podem ser consideradas como determinação externa, uma escolha histórica, e serem percebidas como exterioridades a nossa essência de existir e agir, as quais se convertem então em um obstáculo ao exercício da liberdade, ou, nas palavras de Espinosa, em um constrangimento.

Mais recentemente, pensadores como Marx e Lukács reelaboraram a noção de liberdade em consistência com a concepção descrita - aproveitando também aspectos da concepção mais tradicional (que opõe liberdade à necessidade e à contingência) -, introduzindo a noção de liberdade como possibilidade objetiva. Afirmam que a liberdade é um ato de decisão e escolha entre vários possíveis, não se tratando da liberdade de querer alguma coisa (vontade), mas de fazer alguma coisa (ação). Assim, somos livres para fazer alguma coisa quando temos o poder para fazê-la; somos um poder incondicional de escolhas de quaisquer possíveis. Contudo, nossas escolhas, por sua vez, são condicionadas (no limite dessas possibilidades) pelas circunstâncias físicas, psíquicas, culturais e históricas em que vivemos, isto é, pela totalidade a que pertencemos (CHAUI, 2011, p. 336).

Por fim, Chaui (2008, p. 339) conclui que nosso desejo e nossa vontade não são incondicionados, mas os condicionamentos não são obstáculos impeditivos à liberdade e sim o meio pelo qual ela pode ser exercida, dando um sentido novo ao que parecia fatal, transformando a situação de fato em uma realidade nova, criada por nossa ação. E essa força transformadora, que torna real o que era somente possível e que se achava apenas latente como possibilidade, é o que faz surgir uma obra de arte, uma obra de pensamento ou uma ação direta, como nos movimentos sociais e suas lutas nos marcos das questões de classe social, de etnia e racialidade, de sexualidade, de gênero, de sustentabilidade ambiental, de idade, de regionalidade, de direitos democráticos, de liberdade de expressão, de acesso à informação etc. Nesse sentido, a autora encerra sua abordagem descrevendo quatro momentos desse processo, os quais estão, a nosso ver, em franca sintonia com as etapas do processo de conscientização descrito por Freire (1987, p. 90-95). Tal processo se inicia com a percepção e o destaque da situação-limite dada e impercebida até então pela visão de fundo inicial do contexto, passa pela reelaboração dialógico-crítica do desafio em questão, o que faz surgir o inédito viável como sonho produzido que produz ação e se encerra com o ato-limite transformador, engendrado na práxis social pela qual, ao buscarem a superação da situação-limite, transformam-se também, e sobretudo, as próprias pessoas do contexto da ação-reflexão:

o reconhecimento da contradição entre o ideal e a realidade é o primeiro momento da liberdade e da vida ética como recusa da violência. O segundo momento é a busca das brechas pelas quais possa passar o possível, isto é, uma outra sociedade que concretize no real aquilo que a nossa propõe no ideal. Esse segundo momento indaga se um possível existe e se temos o poder para torná-lo real. [...] O terceiro momento é o da nossa decisão de agir e da escolha dos meios para a ação. O último momento da liberdade é a realização da ação para transformar um possível num real, uma possibilidade numa realidade (CHAUI, 2008, p. 339).

Podemos dizer, então, que, de certa forma, assim como em Boff (2000; 2007), libertação equivale a conscientização, sendo processos permanentes e essenciais, nos quais a dialogicidade se constitui como elemento central do desenvolvimento. Nesse sentido, Espinosa

afirma que o ser humano é mais livre na companhia dos outros do que na solidão e que somente os seres humanos livres são gratos e reconhecidos uns aos outros, porque os sujeitos livres são aqueles que nunca agem com fraude, mas sempre de boa-fé (CHAUI, 2008, p. 340). 
Após esta explanação mais de fundo, retomamos agora a discussão ontológica que vínhamos desenvolvendo, observando que, de um lado, a promoção da redução das barreiras físicas e culturais é continuamente desenvolvida pelo trabalho humano que, se tem a vantagem de lidar com as dimensões do ser-em-si dos objetos e do ser-para-nós de suas representações na consciência, tem a desvantagem de lidar sempre com uma margem de desconhecimento entre os conhecimentos dos quais se acerca para realizar-se, tanto em termos dos condicionamentos envolvidos na ação de transformação (realizada pelo trabalho) como em termos das possíveis consequências destas. Essa condição restritiva de fundo (a ineliminável margem de desconhecimento) requer um contínuo aprimoramento do trabalho, quer nas suas relações metabólicas com o ambiente, quer nas suas relações sociais. Desenvolvimento este que, nessa perspectiva, encontra-se, como vimos anteriormente, em um limiar de sua pré-história, que é dialeticamente o mesmo limiar que, em decorrência, também marca o desenvolvimento do gênero humano, do ser que, assim, estamos nos fazendo historicamente - ser que em sua singularidade constitui o gênero a que pertence e por ele é constituído.

Com isso, em princípio, ao exercermos o trabalho, o fazemos em conformidade com o gênero humano e, reversamente, estando em conformidade com o nosso gênero, trabalhamos, desenvolvendo o trabalho enquanto atividade, e vamos nos fazendo, historicamente, ser social (que só pode ser vindo a ser, em seu inacabamento ontológico). Tal ser tem, em sua ontologia - portanto, necessariamente, como vimos - a liberdade como essência mobilizadora de ações de superação dos desafios que se interpõem em seu caminhar. Podemos, agora, com Espinosa, desdobrar estes desafios em necessidades e em constrangimentos que condicionam a vida, no existenciar de sua materialidade e de sua espiritualidade.

Isso significa que somos livres - necessariamente livres - para escolher nossas ações de transformação. Tais ações podem, por um lado, pôr em curso também as necessárias conexões causais metabólicas e sociais (que não são de caráter teleológico em nenhum sentido), contemplando o que delas conhecemos e preocupando-nos com eventuais consequências do que ainda desconhecemos a seu respeito. Por outro lado, seja no trabalho ou em outro campo de ação, podemos ainda buscar uma condição de superarmos os constrangimentos implicados na realidade (que são, em muitos casos, de caráter teleológico), de modo a nos libertar também de suas amarras restritivas e do sofrimento aparentemente intrínseco a esse caminhar (como, por exemplo, a injustiça social e a degradação ambiental). Destaquemos que, se as necessidades (que são inevitáveis) devem ser conhecidas e atendidas, os constrangimentos (que não são inevitáveis) devem ser conhecidos e superados. Em todo caso, a margem de desconhecimento que atina às conexões sociais, por estas serem marcadas por subjetividades, parece maior e mais desafiadora do que no caso das conexões metabólicas com o ambiente. Daí decorrem, por exemplo, as dificuldades em identificar constrangimentos, como vimos, implicando embates político-ideológicos.

Sendo assim ontológicas, tanto a liberdade que podemos chamar de partida - que, necessariamente, nos constitui, nos termos de Espinosa - como a de busca - que, exercendo a liberdade de partida, além de atender às necessidades e contornar as contingências, retira os constrangimentos - marcam o exercício do trabalho em conformidade com o gênero humano. Esse complexo de relações constitui o que Marx chamou de reino da liberdade e reino da necessidade (aqui incluído o constrangimento). É de acordo com sua tensão que vamos historicamente escrevendo os caminhos da humanidade, que constitui e que é constituída pelo existenciar dialeticamente livre e necessário de cada uma das pessoas viventes e vividas, sempre às voltas, em suas decisões e ações, com os constrangimentos, as contingências, os possíveis, as vontades, com base nas racionalidades culturalmente referidas e sob a égide da ética, da estética e de outras implicações culturais vigentes.

Assim, o trabalho é o meio de nos constituirmos como somos (humanos, sociais - em conformidade com nosso gênero), buscando atender as necessidades e superar os 
constrangimentos interpostos no caminho que pode nos levar ao que aqui chamamos de liberdade de chegada ou plena, que implica uma condição emancipada livre de constrangimentos para existenciar as possibilidades da vida. E, ainda que nos encontremos, como postulou Marx, numa pré-história dessa busca, a possibilidade dessa liberdade de chegada está em nossa essência. Nesse sentido, o ser social "deve conquistar sua própria liberdade através de sua própria ação. Mas ele só pode fazê-lo porque toda atividade já contém, como parte constitutiva necessária, também um momento de liberdade" (LUKÁCS, 2009, p. 242). Momento este que se refere à liberdade de busca, pondo em prática a liberdade de partida na direção da liberdade plena. Tais liberdades, então, aparecem dialeticamente identificadas entre si, constituindo um complexo que podemos chamar simplesmente de liberdade. Daí que faça sentido a frase poética que encerra o documentário Ilha das Flores ${ }^{9}$ : "liberdade - essa palavra que o sonho humano alimenta: que não há ninguém que explique e ninguém que não entenda!" (MEIRELES, 1977, p. 81).

Nessa perspectiva marxiana, a tensão liberdade-necessidade (em que se inclui o constrangimento, nos termos de Espinosa) deve caminhar para além dessa sua fase préhistórica, fazendo com que, um dia (que não é utópico, em seus termos), o trabalho não seja mais apenas meio de nos constituirmos como somos, passando a ser ele próprio um fim em si mesmo, o primeiro carecimento do nosso viver/existenciar. Mas isso só será possível "quando a humanidade houver superado qualquer caráter coercitivo em sua própria autoprodução, só então terá sido aberto o caminho social para a atividade humana como finalidade autônoma" (LUKÁCS, 2009, p. 242) - aqui Marx, na voz de Lukács, coincide explicitamente com Espinosa. E os principais passos desse caminhar decorrem da grande filosofia e da grande arte, que operam na direção do gênero para-si, tornando-nos "interiormente disponíveis para o reino da liberdade" (LUKÁCS, 2009, p. 244). Nesse sentido, Marx, desde jovem, "supôs que a luta de libertação da humanidade culminava na perspectiva segundo a qual os sentidos humanos se transformariam em elaboradores de teorias" (LUKÁCS, 2009, p. 244), uma auspiciosíssima visão, considerando a enorme presença da instrumentalidade da razão nos caminhos de nossos tempos de aqui e agora; mas que nos serve, em consistência ao conceito de humildade em Freire (1987), como indicação das complexidades e das possibilidades que nos atravessam como ser e como gênero.

\section{Algumas considerações}

Para as/os pescadoras/es tradicionais aqui referidos, ser pantaneira/o lhes é, de certa forma, ontológico, um construto em andamento e em plena sintonia com sua ontologia, ainda que não se tenha consciência plena das complexidades e possibilidades implicadas, como vimos. Mais do que uma atividade profissional, a pesca artesanal (aqui implicado o conjunto de saberes que lhe caracteriza) é uma expressão de sua tradição e cultura, faz parte de sua vida comunitária, compõe seu mundo da vida. Ela é, assim, o campo em que se embatem as relações dialéticas e contraditórias que vinculam trabalho e gênero, nos termos anteriormente discutidos, e em que se desenvolvem também as relações dialógicas que, nesta pesquisa, representam alguns passos no caminho marcado continuamente pelo complexo liberdade-necessidade, sob o qual se desenvolve sua permanente luta em serem partícipes ativos, enfrentantes, de seu contexto social e da humanidade em geral.

\footnotetext{
${ }^{9} \mathrm{~A}$ frase de Cecília Meireles foi também usada pelo cineasta Jorge Furtado, roteirista e diretor de "Ilha das Flores", curta-metragem de 1989, filmado em Arquipélago/Porto Alegre, acessível em: $<$ https://www.youtube.com/watch?v=e7sD6mdXUyg>. No filme, a frase é dita na cena em que se vê, em câmera lenta, pessoas trabalhando na catação de resíduo em um lixão, enquanto uma guitarra distorcida e rascante entoa O Guarani, de Carlos Gomes.
} 
Nesse sentido, estão condicionadas/os pelo constrangimento social que "só se pode afirmar por meio da pressão que exerce sobre os indivíduos (frequentemente de maneira anônima), a fim de que as decisões [delas e] deles tenham uma determinada orientação" (LUKÁCS, 2009, p. 231). Assim, elas e eles estão às voltas com esse caráter contraditório de toda práxis social marcada pelas relações de trabalho do capitalismo, sendo impelidas/os "pelas circunstâncias a agir de determinado modo sob pena de se arruinarem. [Elas e] eles devem, em última análise, realizar por si as próprias ações, ainda que frequentemente atuem contra sua própria convicção" (LUKÁCS, 2009, p. 231). Como nos parece evidente, essa dificuldade inerente à práxis social se torna especialmente contundente e desafiadora no contexto da pesquisa.

Para o enfrentamento da situação daí decorrente, destaca-se o fortalecimento coletivo buscado na autenticidade segundo a qual se dispõem em seu mundo da vida, onde a pesca artesanal se converte em seu campo de identificação, em um conjunto de atividades territorialmente articuladas que estão diretamente relacionadas com a garantia do direito humano mais fundamental, que é o direito à alimentação, vinculado ao direito à vida, que antecede a questão da justiça e a dos direitos sociais, de acordo com Ramose (2010, p. 197202). Constitui, sim, em certa medida, aquele trabalho como finalidade autônoma, ou trabalho verdadeiramente humano, a que se referia Marx (2004) desde sua juventude. Atividade por meio da qual o ser se faz e refaz, nela e com ela se identificando, distante dos estranhamentos causados pelo trabalho assalariado intrinsecamente alienante das relações propriamente capitalistas.

Inevitavelmente, a hegemonia do modo de produção capitalista acaba por projetar, de modo anônimo, sua égide desumanizadora, via sistema, por sobre quaisquer mundos da vida já que os mundos objetivo, social e subjetivo estão inseridos na sociedade como um todo, nos termos de Habermas (2012) - e, em particular, sobre o da pesca artesanal que as pescadoras e os pescadores buscam desenvolver em perspectiva ontológica. Tal interferência implica processo de colonização que põe severos obstáculos (constrangimentos) ao exercício pleno dessa tradição, com a qual culturalmente essas pescadoras e esses pescadores se identificam e lutam por reconquistar e manter as mínimas condições necessárias para poderem dar sequência ao existenciar espontâneo de sua natureza, num esforço de autopreservação dos seres que são e da cultura tradicional a que pertencem e que lhes pertence. Essa autoafirmação implica o próprio desenvolvimento eterno e contínuo de si e dessa mesma cultura em que, e por meio da qual, esses seres, cada vez mais raros no mundo contemporâneo, buscam, especialmente na atividade pesqueira artesanal, se fazer e se refazer em conformidade com o gênero humano numa referência do humano preservadamente mais originária, ontológica.

Sua luta no mundo e sua labuta diária, portanto, ainda que sofram as restrições cada vez mais coercivas do capitalismo globalizado em que vivemos todas/os, estão, por outro lado, conectadas com o que há de mais profundo em nossos sentidos de existir; estão voltadas às questões mais complexas e ousadas emanadas das nossas relações com a natureza como totalidade a que pertencemos; seus movimentos buscam, especialmente na pesca artesanal, a satisfação de necessidades, a convivência com contingências e a superação de constrangimentos, em processo que ao mesmo tempo engendre identidade de ser e volte-se a um horizonte no qual reside, em potência circunstancialmente adormecida, a possibilidade daquela liberdade plena, livre de constrangimentos. Daí a força de seu impulso mobilizador e esperançoso que se encontra nas entrelinhas de sua simplicidade corporal e linguística, de pouca visibilidade e pouco reconhecimento no mundo em geral.

A pesca tradicional é, essencialmente, caracterizada por seu aspecto sociocultural, fundamentalmente dependente dos territórios pesqueiros (DIEGUES, 2002; SOUZA; LOGAREZZI 2017, p. 124). A tradição pesqueira pantaneira, materializada na relação com o ambiente físico, nas estratégias de pesca, nas formas solidárias de comercialização e nos modos 
de ocupação do rio e de suas margens, representa uma expressão fundamental dos processos educativos intrínsecos às práticas sociais dessas comunidades no Pantanal em Cáceres, no Mato Grosso. Em grande medida, há nesses processos educativos uma intencionalidade educativa enfrentante que denuncia a inação propositada do Estado e as intromissões do capital (SOUZA, 2017) - as quais resultam em constrangimentos diversos à vivência cultural local - e, em contrapartida, anuncia, em novas ações, a busca por outras possibilidades de ser, com base em nossa potencialidade ontológica de liberdade. As/os pescadoras/es artesanais têm, nesse conhecimento tradicional, entretecido em sua memória coletiva, uma de suas principais fontes de informação, manutenção de sua cultura e conservação da biodiversidade. Seu cotidiano é caracterizado pela resistência e luta pela manutenção de seus territórios de pesca e da proteção de seu patrimônio cultural material e imaterial, essencialidades da identidade que tanto lhes é cara, como vimos. Dessa forma, buscam perseverar como seres sociais que agem em conformidade com seu gênero, para cuja generidade contribuem consistente e permanentemente com seu trabalho e suas ações, sob a égide do que chamamos ética tradicional ribeirinha pantaneira, para a qual aqui procuramos abordar alguns fundamentos teóricos.

\section{Referências}

BOFF, L. Ética da vida. 2. ed. Brasília, DF: Letra Viva, 2000.

BOFF, L. A águia e a galinha: uma metáfora da condição humana. 45. ed. Petrópolis: Vozes, 2007.

CHAUI, M. Convite à filosofia. 13. ed. 7. imp. São Paulo: Ática, 2008.

CHAUI, M. Desejo, paixão e ação na ética de Espinosa. São Paulo: Companhia das Letras, 2011.

DIEGUES, A. C. S. O mito moderno da natureza intocada. 3. ed., São Paulo: Hucitec, 2001.

DIEGUES, A. C. S. (Org.) Povos e águas: inventário de áreas úmidas brasileiras. 2. ed. NUPAUB-USP, 2002.

FERNANDES, F. Capitalismo dependente e classes sociais na América Latina. 4. ed. São Paulo: Global, 2009.

FOLADORI, G. Limites do desenvolvimento sustentável. Tradução Marise Manoel. Campinas: Ed. da Unicamp, 2001.

ESPINOSA, B. Ética. Tradução Tomaz Tadeu. 2. ed. Belo Horizonte: Autêntica, 2008.

FREIRE, P. Extensão ou comunicação? Tradução Rosisca Darcy de Oliveira. 13ª ed. Rio de Janeiro: Paz e Terra, 1977.

FREIRE, Paulo. Pedagogia da esperança. 12a ed. São Paulo: Paz e Terra, 2005.

FREIRE, P. Pedagogia do oprimido. $38^{\mathrm{a}}$ ed. Rio de Janeiro: Paz e Terra, 1987.

HABERMAS, J. Teoria do agir comunicativo. v. 1. Racionalidade da ação e racionalização social. Tradução Paulo Astor Soethe. São Paulo: WMF Martins Fontes, 2012.

PINHO, C. R. S.; IRIGARAY, C. T. J. H.; SILVA, C. J.; SOUZA, S. C. As comunidades tradicionais pantaneiras no contexto da política nacional de desenvolvimento sustentável dos povos e comunidades tradicionais. In: SILVA, C. J. SIMONI, J. (Org.). Água, biodiversidade e cultura no Pantanal. Estudos 
ecológicos e etnobiológicos no sistema de Baías Chacororé: Sinhá Mariana. Cáceres: Ed. Unemat, 2012. p. 207-220.

GRUPPI, L. O conceito de hegemonia em Gramsci. Rio de Janeiro: Graal, 1978.

LOGAREZZI, A. J. M. Outras considerações: dialética e diálogo em Marx e em Freire. In: LOGAREZZI, A. J. M. O trabalho em Marx e a questão ambiental: fundamentos e atualidade. 2015. 114 p. Relatório (Pós-doutorado em Sociologia) - Universidade Federal de São Carlos, São Carlos-SP, 2015. p. 97-114.

LUKÁCS, G. O jovem Marx e outros escritos de filosofia. Tradução Carlos Nelson Coutinho e José Paulo Neto. 2 ed. Rio de Janeiro: Ed. UFRJ, 2009. 256 p. (Pensamento Crítico, v. 9)

LUKÁCS, G. Prolegômenos para uma ontologia do ser social. Tradução Lya Luft e Rodnei Nascimento. 1. ed. São Paulo: Boitempo, 2010.

MARX, K. Manuscritos econômico-filosóficos. Tradução Jesus Ranieri. São Paulo: Boitempo, 2004. $175 \mathrm{p}$.

MEDEIROS, H. Q. Impactos das políticas públicas sobre os pescadores profissionais do pantanal de Cáceres - Mato Grosso. 1999. 217 f. Dissertação (Doutorado em Ciência Ambiental) - Universidade de São Paulo, São Paulo, 1999.

MEIRELES, Cecília. Romanceiro da Inconfidência. Rio de Janeiro: Nova Aguiar, 1977. Disponível em http://professor.pucgoias.edu.br/SiteDocente/admin/arquivosUpload/5628/material/Cec\%C3\%83\%C2 $\%$ ADlia\%20Meireles\%20-

$\% 20$ Romanceiro\%20da\%20Inconfid\%C3\%83\%C2\%AAncia\%20[Rev][1].pdf . 239 p.

RAMOSE, M. B. Globalização e Ubuntu. In: SANTOS, B. S.; MENESES, M. P. (Org.). Epistemologias do sul. São Paulo: Cortez, 2010. p. 175-220.

SOUZA, S. C. Educação ambiental dialógico-crítica no Pantanal de Mato Grosso: a voz e o silêncio das pescadoras e dos pescadores tradicionais. 300 p. Tese (Doutorado em Ciências Ambientais) - Universidade Federal de São Carlos, São Carlos-SP, 2017.

SOUZA, S. C.; LOGAREZI, A. J. M. Educação ambiental dialógico-crítica com comunidades tradicionais no Pantanal de Mato Grosso: a solidariedade e os enfrentamentos nas práticas sociais. Ambiente \& Educação, Rio Grande, v. 22, n. 1, p. 111-131, 2017.

SOUZA, S. C.; LOGAREZZI, A. J. M. Educação Ambiental e participação comunicativa: diálogos com pescadoras/es artesanais no Pantanal de Mato Grosso. Revista Brasileira de Educação Ambiental, São Paulo, v. 13, n. 1, p. 332-353, 2018. 